\section{A mídia e a produção de modos de ser da adolescência}

\section{RESUMO}

O foco desta discussão é problematizar de que modo determinadas práticas cotidianas forjam marcas identitárias, produzindo determinados modos de ser adolescente. $\mathrm{O}$ objetivo é circunscrever como práticas de significação na contemporaneidade produzem regimes de verdade que marcam corpos e comportamentos, governam modos de viver e de se perceber de adolescentes, fundamentando, principalmente, na cultura a partir do campo dos Estudos Culturais e na discussão foucaultiana sobre 0 conceito de discurso. 0 material de análise sustenta-se em uma reportagem, do dia 7 de dezembro de 2003 de um veículo de comunicação de ampla circulação no RS, a qual apresenta uma classificação realizada por adolescentes e que propõe códigos de comportamentos usando como critérios o vestuário e a aparência do corpo.

\section{ABSTRACT}

This discussion aims to problematize the ways in which certain everyday practices construct identity markers, therefore producing ways of being a teenager. We seek to circumscribe how practices of signification in the contemporary produce truth regimes that mark bodies and behaviors governing ways of living and perceiving teenagers. This discussion is based in the conception of culture derived from the field of Cultural Studies and also from the foucaultian discussion of discourse. The analysis material is based on a newspaper article published on December, $7^{\text {th }}, 2003$, in which a classification made by adolescents is presented establishing behaviour codes focusing on body appearance and clothing.

\section{PALAVRAS-CHAVE (KEY WORDS)}

- Jornalismo (journalism)

- Narrativa (narrative)

- Jornalismo comunitário (communitary journalism)

\section{Neuza Maria de F. Guareschi PPGP/PUCRS}

"Populares, excluídos e NeUtros. Divididos em castas, certos adolescentes topam correr riscos e até perder a identidade para serem reconhecidos pelo grupo" ${ }^{1}$. Esta é a chamada que abre a reportagem da capa do caderno Donna $\mathrm{ZH}$ do dia 07 de dezembro de 2003. É também, o que nos chama a problematizar de que forma determinadas práticas culturais cotidianas forjam marcas identitárias, e por conta disso, modos de viver.

A reportagem é elaborada a partir de entrevistas com adolescentes de classe média do município de Porto Alegre, intercalada por prescrições e aconselhamento de especialistas (aos pais) para que estes não percam o controle sobre seus filhos.

Aos adolescentes "prescrevem-se estratégias usadas hoje para chamar a atenção do grupo e virar popular". Mais que isso, "apresenta-se" a estes três possibilidades de ser adolescente: ser populares, excluídos ou neutros!

A proposta deste trabalho é discutir como estas classificações dos modos de ser adolescente passam a ser naturalizadas e produzem ou evidenciam formas de ser adolescente que instituem um referente e seus diferentes e, como tais classificações tomadas como naturais, geram processos de desigualdade social e excluem outros modos de ser, ditando aos sujeitos seu enquadramento em uma das categorias apresentadas.

Embora possamos encontrar uma série de outras marcas identitárias pelas quais os adolescentes têm-se produzido, a reportagem menciona e, portanto, faz existir, apenas três, e sutilmente nos diz: se você é adolescente deve estar em uma delas. 
A culfura como constituinte do sujeito

Este trabalho é pensado a partir da noção do entendimento sobre os conceitos de cultura, discurso e marcadores identitários. A discussão sobre cultura é realizada pelo campo dos Estudos Culturais e por alguns autores $^{3}$ que propõem uma aproximação desse campo com a perspectiva pós-estruturalista, tomando Michel Foucault como um de seus interlocutores.

A cultura é um dos operadores conceituais centrais para os Estudos Culturais por se apresentar tanto em um sentido "substantivo" quanto em um sentido "epistemológico". "Substantivo" ao se localizar na estrutura empírica e na organização das ações, instituições, relações sociais. "Epistemológico" por transformar as formas de conhecimento e conceitualizações que modificam a própria experiência. A mídia contempla ambos os sentidos ao se constituir como uma prática "concreta" que produz modos de pensar e conhecer. Hall (1997) enuncia que essas duas proposições envolvem a nova formulação do sentido de cultura a partir de uma mudança paradigmática nas ciências sociais e humanas, identificada como "virada cultural" onde ela passa a ser compreendida como posicionando o sujeito e produzindo modos de vida.

A primeira proposição refere-se à definição antropológica de cultura em que esta é tomada como prática. Dentro dessa perspectiva antropológica, a cultura é entendida como um conjunto de normas, valores, regras, costumes, artefatos de criação e o cultivo e produção dos diversos modos de vida dos diferentes grupos sociais. Nessa compreensão o sujeito produz e reproduz a cultura, mas é tomado como algo ao lado ou fora dela e não como constituído nela.

A segunda questiona o significado antropológico de universalidade da cultura por meio dos conceitos de formação social, relações de poder, dominação e regulação, resistência e luta. Ou seja, cultura passa a ser objetivada como um território de lutas e contestações através do qual se produzem tanto os sentidos quanto os sujeitos que constituem os diferentes grupos sociais.

Essa mudança na conceituação de cultura ampara-se na idéia de Hall (1997, p. 16) de que "os seres humanos são seres interpretativos, instituidores de sentidos" reafirmando assim, que a "realidade" é uma proposição explicativa, é uma interpretação que institui códigos, sistemas de significação que dão sentido às nossas ações e às ações alheias. A esse conjunto de ações codificadas nomeamos de cultura, resultando que "toda a ação social é cultural, que todas as práticas sociais expressam ou comunicam um significado e, neste sentido, são práticas de significação" (Hall, 1997, p. 16). Desse modo, a noção de cultura ultrapassa o domínio material, da atividade artificial da experiência humana para o domínio do simbólico de dar sentido, de construção de significados. Não se quer dizer aqui, que a cultura não tenha sido em outros momentos reconhecida na sua dimensão simbólica. O que se pretende é enfatizar que ao se construir sentidos sobre as práticas os sujeitos produzem a cultura e a si mesmo. Ela é tomada como práticas sociais que, ao forjarem sentidos, ganham efeitos de verdade e instituem modos de viver, de ser, de compreender, de explicar a si mesmo e o mundo. Conforme Fischer (2001, p. 25):

Assumimos, com esse autor, uma concepção bem ampla de cultura: chamaremos de cultura o conjunto complexo e diferenciado de significações relativas aos vários setores da vida dos grupos sociais e das sociedades e por eles historicamente produzidas como as linguagens, a literatura, as artes, o cinema, a TV, o sistema de crenças, a filosofia, os sentidos dados às diferentes ações humanas, sejam estas relacionadas à economia, à medicina, às práticas jurídicas, e assim por diante.

Em outras palavras, concebemos a cultura como constituidora de sujeitos, 
produtora de identidades e da relação com o outro. Mas a compreensão dessas proposições sobre cultura só se torna possível se assumirmos a centralidade da linguagem como sistema produtor disso que chamamos "realidade". "A linguagem não é unicamente um meio de exposição. Falar equivale a construir o mundo, e o uso da linguagem sempre deve ser visto como uma forma de ação" (Iñiguez, 2002, p. 136). O imbricamento das concepções de cultura e linguagem remete a noção de um sistema codificador, produtor de sentidos, não como termo abstrato, mas sim como práticas cotidianas, organizadas e vividas e que não agem especificamente sobre a vida, mas sobre os modos de viver, de se tornar o que se é.

É preciso ter cuidado com essa definição de cultura, pois facilmente escorrega-se em uma determinação da mesma como reprodutora das relações sociais assimétricas e esta será justamente uma das críticas feitas pelos Estudos Culturais às teorias de cunho marxista. Isso por compreenderem que quando se fala de um sistema cultural, não se quer fazer alusão a uma superestrutura que determina e reproduz todas as relações e práticas sociais, visto tratar-se de negociação de sentidos ${ }^{4}$ em um território de lutas e contestações pelos quais nos tornamos sujeitos.

Cultura, então, não é reprodução social nem tampouco relativa única e exclusivamente aos bens materiais; é sim, produção de sentidos forjados pela atividade humana. Desta forma, a cultura deve ser analisada no próprio contexto do qual emerge. Mas é importante atentar-se de que a compreensão do contexto histórico não diz respeito à descrição e análise de fatos e acontecimentos e sim, de como o campo social produz e modifica fatos e acontecimentos: como esse campo possibilita o aparecimento destes e como passa a se falar sobre os mesmos.

Assim, a cultura é correlata de determinados campos de saber (Sociologia, Antropologia...), cuja operacionalidade se dá através de redes discursivas, ou seja, de formações discursivas que inventam as categorias das quais se ocupam. Pode-se dizer que o discurso cria os referentes que possibilitam operar com a "realidade" sem tomá-la como representação, mas marcadores em relação aos quais os sujeitos passam a reconhecer-se ou diferir-se. Isso lhes possibilita posicionar-se na rede discursiva, constituir-se como sujeitos a partir daquilo que lhes interpela como sendo dito com respeito a si.

A concepção de discurso utilizada aqui se faz importante e se fundamenta, principalmente, na formulação foucaultiana desse conceito na qual este passa a ser considerado como prática que forja os objetos dos quais fala. O discurso é, portanto, produtor de formas de inteligibilidade, de proposições explicativas e de atos de significação que cria ou possibilita o aparecimento de seus correlatos. Estes não são pré-existentes, não são naturais, são, antes de tudo, invenções. Tais invenções, tais emergências de sentido do discurso, produzem-se segundo determinados códigos e convenções, segundo um sistema de regras e condições de formulação que os coloca em jogo no campo social. Ao serem tomados como legítimos tais discursos passam a funcionar como regimes de verdade construindo o que tomamos por verdadeiro, falso, científico, válido, etc.

Se entendermos as práticas culturais como discursos, estes colocam em funcionamento um universo próprio de práticas de significação que se inscrevem nos sujeitos e se tornam discursivamente "reais". Portanto, como esclarece Santos, (1997) é importante:

Explicar como o discurso se faz carne, como o corpo incorpora/encarna as marcas de uma cultura. Ou ainda, como nos reconhecemos como sujeitos de um determinado discurso sobre o corpo. Esse discurso nomeia, hierarquiza, atribui valores, distribui significados e, dessa forma, por aqui- 
lo que ele enuncia e por seus aparatos, imprime em cada um de nós modos de nos conhecermos (p.85).

Nesta direção, os discursos que produzem uma determinada adolescência dizem respeito à possibilidade de determinadas verdades tais como cabelo alisado, utilização de maconha, perda da virgindade, tornarem-se referentes de classificação de pertencimento ou não a um grupo. Forjam identidades a partir de marcadores que culturalmente passam a ser definidos como relevantes. Ao delimitar comportamentos, modos de ser e agir, os discursos estabelecem normas, padrões, instauram referenciais identitários e, ao mesmo tempo, afirmam e constituem aquilo que é diferente a esta identidade, que não é apenas o seu oposto, mas é tudo aquilo que não está incluído nesta referência. Esta dinâmica de significação e demarcação de diferenças, central para as teorias pós-estruturalistas, será fundamental no processo de construção e constituição de identidades. Dito de outro modo, à medida que essa discursividade encontra repercussão no tecido social ela alimenta práticas e produz sujeitos que passam a agir e reconhecer-se a partir de determinadas posições, tais como os "populares", os "neutros" e os "excluídos", conforme sugere a reportagem em questão, embora possamos pensar em uma gama de outros modos de ser adolescente que não ganham visibilidade na mesma.

Tais marcadores identitários delineiam-se a partir de relações de poder que transversalizam a produção cultural das diferenças. Têm o poder de definir identidades, marcar diferenças e estabelecer um padrão de normalidade ou referência. De acordo com Íñiguez (2002, p. 122): “Nas conformações convencionais do mundo, certas agências sociais, certos agentes sociais, têm mais poder que os outros". Quando refiro a uns com mais poder do que outros, estou me referindo à possibilidade de persuasão, incitação e legitimação de determinadas "verdades" por determinados grupos sociais. As relações de poder estão presentes não apenas porque determinados adolescentes impõem mais determinados modos de ser, mas também porque estes (e seus outros) são provocados cotidianamente por discursos que circulam na mídia, como telenovelas e programas direcionados ao público jovem que sugerem como vestir, como viver, como falar, etc., e que produzem os padrões do que é belo, do que é "cultuável". Instituem os modos de ser jovem e as referências para adolescentes classificarem-se e classificarem os outros em categorias que operam a partir da demarcação de diferenças. As identidades são, portanto, forjadas a partir das diferenças e estas passam a instituir desigualdades, na medida em que, adolescentes adotam classificações de pertencimento que incluem alguns e excluem outros: "Nós, os populares, temos que acabar c/ esses excluídos... Tô boba como tem gente que acha que a gente excluí vocês sem motivo... Os porquês da exclusão normalmente são o fato de vcs serem patéticos, ridiculos, bananas... e copiarem os populares".

Como se pode observar nas enunciações dos adolescentes e do próprio jornal que publicou a reportagem, criam-se categorias sociais dentro de um mesmo território, ou seja, a luta por imposições de sentido dá-se, neste caso, no interior de uma população de classe média, que freqüenta escolas privadas do município. As categorias que surgem - populares, neutros e excluídos - marcam a diferença entre os modos de ser e de viver, o que consumir, de que forma consumir, naturalizando essas marcas, de modo a criar segregações dentro de um mesmo território. Naturalizam-se os populares, os excluídos e os neutros (os outros) como se houvesse uma "essência" de cada um destes modos de se viver à adolescência, ou mesmo como se estes modos fossem os únicos possíveis e só a partir deles os adolescentes pudessem constituirse como tais.

Não se pode esquecer que os adolescentes são interpelados cotidianamente por pluralidades discursivas. São sentidos for- 
jados pela mídia, pela pedagogia, pela psicologia, pela medicina, pelo esporte, entre outros produtos culturais, que atravessam os espaços em que estes adolescentes circulam, tais como as escolas, as festas, os bares, a internet, os clubes, os shopping centers e a própria família. Existe, na contemporaneidade, uma intensificação da quantidade e da velocidade com que as informações circulam, em grande parte em função da rapidez e globalização dos meios de comunicação atuais e da sofisticação da tecnologia. De maneira muito veloz, sussurros tornam-se eventos e acontecimentos transformam vidas cotidianamente. Os jovens são tomados por e (re)produzem discursos sobre o que comer e como comer, o que vestir e como vestir, o que ler, o que ouvir, o que ver, com o que se interessar, como viver enfim constituindo um modo hegemônico de ser e de se entender a adolescência. $\mathrm{O}$ contemporâneo é marcado mais por uma série de prescrições do que propriamente pela disciplina, mesmo que essas prescrições acabem por impor disciplinamento dos sujeitos quando pensamos que muito cedo, meninos e meninas, já se ocupam, por exemplo, de uma alimentação regrada, com valor nutricional elevado e baixas taxas de gordura, etc.

Porém, os efeitos e os sentidos destes discursos, e mesmo os próprios discursos, estão sempre em transformação. A utilização da maconha e a perda da virgindade que nos anos sessenta e setenta marcaram uma forma do que se nomeava de contracultura, atualmente caracteriza-se justamente como um modo de tornar-se padronizado. As vestimentas hippies, que eram sinônimos de resistências aos valores capitalistas, hoje se encontram à venda em lojas de griffe e são chamadas de "hippie-chic". Além disso, esses dois vetores de subjetivação: o uso da maconha entre outras substâncias e a perda da virgindade, são considerados por estes adolescentes como a mostra da falta de controle dos pais, o que acaba por recrudescer os investimentos pedagógicos, jurídicos e psicológicos nas fa- mílias, considerando-as como responsáveis pela formação dos jovens.

Dessa forma, algumas produções culturais dos jovens, bem como da criação de determinadas classificações e formas de resistência, é entendida a partir da noção de cultura enquanto um território de lutas e negociações de sentidos que implica, inevitavelmente, em relações de poder, compreendido como força; um poder extensivo a todo o tecido social e as de formas de viver. Para apreender o poder como força, é importante considerá-lo como positivo, como produtivo, visto não impedir a ação alheia, mas ao contrário, a incitar. Assim, para se falar em poder como positividade é indispensável que o "outro" sobre o qual o poder se exerce seja reconhecido como sujeito da ação, pois é sobre essa possibilidade de ação que a outra ação afetará. O estabelecimento de categorias como os populares, os neutros e os excluídos, não deixam de constituir-se em formas de reconhecimento destas alteridades, ainda que fundadas em relações de desigualdades e não apenas de diferenças. As práticas culturais que constituem esses jovens adolescentes são formas de dar sentidos em que se tenta fazer valer significados particulares, próprios de grupos sociais, sobre os significados de outros grupos.

\section{Práticas de significação e a construção de modos de viver}

O que se observa na reportagem que tomamos para essa discussão sobre jovens adolescentes é, justamente, o que podemos chamar de uma tentativa de obliteração da diferença, na medida em que a classificação por grupos a que se pertence tem como meta a caracterização do que vem a ser "popular". As três categorias - popular, excluído e neutro - são criadas a partir de práticas cotidianas como: alisar cabelo, perder a virgindade, fumar maconha, usar determinadas roupas que poderiam ser tomadas como possibilidade de produção de di- 
ferença, mas que acabam por estabelecer um referente do qual partem - o ser popular - mesmo não o sendo. A classificação parte desses critérios e não de outros que marcariam justamente outras formas de produção de si. Os marcadores identitários, considerados critérios de pertencimento, recrudescem um processo de normatização desses adolescentes "Eu tava observando: vocês não conseguem parar de falar da gente não?? A-C- O-R-D-E-M, seus excluidinhos... Vocês não se enxergam? (...) O meu natural é de chapinha e unhas feitas e daí? Algum problema? Patty é um estilo, uma maneira pink de ver a vida!! (...) Porque no fundo é o que você queria ter garota ... (...) sua inveja é meu ibope!!!".

Podemos, também, pensar sobre as políticas de identidade que nascem das lutas por imposições e negociações de sentidos. Ao se construir sistemas de significação que pretendem expressar os modos de viver dos grupos de acordo com critérios ditos como reais, como materiais, como anteriores à experiência que se faz deles, essas classificações dos adolescentes categoriza os modos de viver como se estes fossem naturais: "o colégio não tem uniforme oficial, mas tem o uniforme dos alunos. Se a líder vem de chinelos de dedo num dia, no outro todo mundo virá assim também, mesmo que ache ridículo". Essas imposições e negociações de sentidos são muitas vezes desconsideradas ou ignoradas, na medida em aquilo que é tido como "normal" e "natural" não é percebido como construído pelos adolescentes, ao mesmo tempo em que os conforma. Isso, no entanto, não anula os movimentos de resistência. Assim as políticas de identidades surgem neste cenário em que os adolescentes tentam impor determinadas práticas culturais como categorias universais, naturais e pré-estabelecidas. Desta forma, consistem nos processos de grupos sociais e culturais como forma de resistência em relação à universalidade dos sentidos e às desigualdades sociais produzidas culturalmente pelos sistemas de significação que pretendem expressar o humano e o social em sua totalidade: "Acho que todos os excluí- dos devem dar a volta por cima e fazer como eu fiz: levanto a cabeça e sigo em frente. Se houver pedras no caminho eu chuto e continuo seguindo o meu caminho!".

Diante disso, podemos pensar as políticas de identidades como movimentos de contestação que não se fazem pelo igual, mas pela diferença, não são lutas pela imposição da supremacia de uma identidade, ou categorias, mas constituem-se justamente na diferença, naquilo que não são, não em termos materiais, mas em termos discursivos (Guareschi 2000). As diferenças não implicam apenas ou necessariamente no fortalecimento de uma ou outra identidade, o que resultaria na naturalização das mesmas, mas no contínuo processo de desestabilização dos marcadores identitários: abalam as identidades descentrando-as constantemente e engendrando novas posições de sujeitos, uma multiplicidade de posições que se articulam com o diferente o que nos leva, também, a pensar a identidade não como uma unicidade, idêntica, mas como fluida e descontinua. Da mesma forma, nos leva a entender de que não existe uma identidade de adolescente enquanto única ou fixa.

Duschatzky e Skliar (2001), ao problematizar nossas formas de relação com a identidade e diferença apresentam três versões discursivas sobre como o outro diferente tem sido tomado em nossa sociedade: como fonte de todo mal, como sujeito pleno de um grupo cultural ou como alguém a tolerar. O primeiro sentido, o outro como fonte de todo mal (ou de todo o bem), implica tomar as identidades como fixas, centradas, homogêneas e estáveis, e opera uma lógica de binarismos, ou seja, o que não é bom é mau, o que não é popular é excluído; o que não é negro é branco; o que não é homem é mulher. A segunda forma, o outro como sujeito pleno de uma marca cultural indica uma concepção em que as diferenças culturais são absolutas e as identidades constroem-se em referenciais únicos, sejam étnicos, de gênero, de raça, de classe social entre outros. A terceira for- 
ma de tomar o outro, que os autores chamam de "o outro como alguém a tolerar", é uma versão que por vezes obscurece que as culturas "são lugares de sentido e de controle", que a tolerância "pode materializar a morte do vínculo social sempre conflitivo. "A tolerância despoja os sujeitos da responsabilidade ética frente ao social e libera o Estado da responsabilidade institucional de encarregar-se da realização dos direitos sociais" (Duschatzky e Skliar, 2001, p. 135-136).

Em relação ao primeiro modo de posicionarmos o outro, fonte de todo o bem ou todo mal, podemos pensar que tanto os adolescentes populares quanto os excluídos podem ser posicionados como fonte de todo bem ou de todo mal. Esse processo de marcação de identidades fixas pelas práticas cotidianas em relação ao grupo dos populares e excluídos é apontado por uma menina de 15 anos entrevistada da reportagem: "Sempre fiz parte da turma dos conhecidos, porque sempre fui diferente. Sempre tive algo para chamar a atenção, porque sempre tive necessidade de chamar a atenção. Existe, sim, isso de ser popular, porque se tu andar em um colégio sempre vai ter a turma dos excluídos". Desta forma, o que é diferente aos binários é também o que não faz parte da maioria e a maioria é homogeneizada, pertence ao que é igual por ser idêntica.

Se pensarmos a partir da segunda versão proposta por Duschatzky e Skliar (2001), veremos que as categorias populares e excluídos são formas de caracterização de um sujeito pleno na medida em que se utilizam de um referencial único, tal como as vestimentas e o comportamento. Ou seja, o outro, tanto no caso o excluído quanto do popular, é conformado a partir do que veste e dos modos de viver: transar, fumar maconha, matar aula, consideradas diferenças absolutas que definem o outro em sua suposta totalidade. "A radicalização desta postura levaria a exagerar a identidade do outro ou a encerrá-la em pura diferença. Desse modo, permaneceriam invisíveis as relações de poder e conflito e se dissolveriam os laços de vinculação entre sujeitos e grupos sociais" (Duschatzky e Skliar, 2001, p. 128).

A terceira forma de tomar o outro ganha visibilidade pela afirmação de que os neutros são aqueles que "não despertam nem desprezo nem admiração". Neste caso, a categoria neutro é tanto um grupo que é tolerado pelo popular quanto um grupo que tolera os outros. Para ser neutro o adolescente deve chamar a menor atenção possível, a diferença não deve ser uma marca, pois no momento em que esta se torna fonte de ocupação, deixa de ser neutro e tolerado, para tornar-se excluído ou popular. Porém, como o referente é o popular, mesmo o neutro sendo tolerado e tolerando os outros, há sempre a iminência de deixar de ser o que é para tornar-se popular ou excluído, pois como é escrito na reportagem: "A divisão de castas é dinâmica".

De acordo com Duschatzky e Skliar (2001, p.135),

As culturas não são essências, identidades fechadas que permanecem através dos tempos, mas são lugares de sentido e de controle que podem alterar-se e ampliar-se em suas diferentes interações. Algumas culturas podem ser excludentes. Desta forma a tolerância pode debilitar a capacidade de perceber as diferenças discursivas e mascarar as desigualdades.

Assim, a tolerância está associada ao ato de aceitar o quase inaceitável; é uma condição limite. Como o neutro, o popular também é uma condição de limite na medida em que pode deixar de se-lo a qualquer momento mediante determinadas práticas que o tornem excluído ou neutro. A tolerância é uma concessão e só a concede quem exerce o poder de tolerar. As categorias criadas pelos jovens nas escolas, na internet, nas festas ou em outros espaços em que circulam, acabam por legitimar determinados grupos como aqueles que ditam modas e regras, o que lhes cabe decidir 
quem é uma coisa ou outra, quem deve ser tolerado ou não. Isso não é uma especificidade de adolescentes que não têm limites por terem pais ou mães ausentes, mas antes de tudo, de um grupo social que é interpelado pela "necessidade" de consumo e acesso a determinados bens culturais e sociais que marcam os sujeitos e seus modos de viver. Por exemplo, nos anos 60 e 70 , liberdade era ter uma calça azul desbotada como anunciava o jingle de uma propaganda de jeans. Já nos anos 90, liberdade era transar até o final do ensino médio e usar roupas de determinadas grifes. Os sujeitos são produzidos por aquilo que vestem, alimentam, sentem, desejam, ou como coloca Bauman (2001), ser sujeito hoje é consumir.

Outro aspecto da reportagem em questão é a forma como apresenta os modos como os discursos pedagógicos e psicológicos marcam os populares e excluídos: "Para os especialistas, é fácil identificar quem são os adolescentes com mais chances de se tornar vítimas da turma: os tímidos, os de baixa auto-estima, os que não se destacam em nenhuma área e têm pais ausentes - principalmente a figura paterna. Nesse contexto o adolescente fica sozinho e sem limites"... Ou, segundo a avaliação de outra especialista: "no consultório já passaram diferentes pacientes com histórias muito parecidas - gurias de 15 anos, com um histórico de mais de uma dezena de parceiros, algumas tendo, inclusive, experimentado drogas".

As enunciações sobre educação e controle que recaem sobre os adolescentes e dizem respeito também à forma dos pais e mães lidarem com isso, remetem a prescrições de especialistas de como as famílias devem responsabilizar-se pelos cuidados/ educação de seus filhos: "Com pai e mãe atentos e por perto, o jovem se sente mais seguro para ser ele mesmo, sem necessidade de imitar ninguém". Ou: "Há adolescentes que têm pais presentes e planos para o futuro". Desse modo, ser popular ou ser excluído também diz respeito ao modo como os pais relacionamse com os filhos. Estes também passam a ser considerados os responsáveis por essas categorizações como explicita a fala de uma menina de 15 anos: "Mas os pais não têm controle de nada, os meus nunca vão ter. Pai e mãe não impõem mais respeito, não sabem educar".

As prescrições que aparecem na reportagem, não dizem respeito apenas aos jovens, mas também, aos seus pais e mães. Essas questões são ainda reforçadas pela produção da reportagem em um quadro onde indica aconselhamentos para os pais e mães: "não se esquive da tarefa de acordar de madrugada para buscar seu filho nas festas e faça questão de que ele receba os amigos em casa; fique atento se, de uma hora para outra, o adolescente trocar o melhor amigo de infância por outro; repare se o adolescente mudar de repente o jeito de vestir; fique atento se seu filho começar a se irritar por nada, perder o apetite, ou comer em demasia; jovens podem superar frustração; seja companheiro; incentive seu filho a buscar atividades que lhe dêem prazer e reconhecimento".

Aos adolescentes prescreve-se uma dietética para deixar de ser excluído que, segundo a reportagem, segue as seguintes regras: vestir roupas das marcas de moda, respeitando os códigos do que é certo e errado. Há regra até para o comprimento da calça - o salto do tamanco das meninas (comprado em uma das lojas de sapato mais caras) não deve aparecer; matar aula para ficar paquerando ou batendo papo com os amigos; desafiar os professores e debochar dos colegas - vale humilhar e ofender; namorar ou ficar com alguém popular; ficar com muitos caras ou muitas gurias em uma mesma festa; tomar porre na festa; usar drogas, se essa for uma prática da turma.

Ao se entender que os comportamentos dos adolescentes aconteçam devido à ausência de uma referência familiar articulam-se enunciações do campo da Psicologia que alertam para o fato dos adolescentes voltarem-se de sobremaneira para seus grupos e passarem a reproduzir determinados comportamentos. Esses discursos acabam por incitar a forma como esses adolescentes pensam a respeito de si mesmo e o outro, marcando seus corpos e modos de vida. "Todo mundo fuma e bebe para ser aceito", não é uma enunciação da adolescente, mas 
daquilo que se constitui como sendo o adolescente e a adolescente do grupo popular. Retomando, então, uma das propostas inicialmente apresentadas neste trabalho, proponho que possamos discutir como construções, como a destas categorias de adolescentes, mas não apenas estas, na medida em que cotidianamente estamos construindo uma infinidade de outras formas de classificação, podem, ao naturalizarem-se, alimentar relações de desigualdade (HÜNING, 2003). Digo isso porque, quando essencializamos as categorias identitárias ou as diferenças, tornamos invisíveis as condições de emergência das mesmas, as relações de poder que se dão no campo da cultura, implicadas na constituição das mesmas. Ao naturalizá-las destituímos os sujeitos classificados, ou diminuímos suas possibilidades de ação. Universalizamos marcadores identitários e reduzimos os sujeitos aos mesmos. Assim, tendemos a engessá-los em determinadas posições e instituir ou reafirmar relações assimétricas. Essa problematização deve estar presente em nossas reflexões para não cairmos na ingenuidade de acreditarmos que se trabalhamos, discutimos ou, às vezes, apenas mencionamos a diferença, estamos promovendo o "empoderamento" dos sujeitos sobre os quais falamos. Pelo contrário, é pelos modos como tomamos a questão da diferença e das identidades que criamos ou barramos as possibilidades de ação dos sujeitos, instituímos ou transformamos as relações de desigualdade social. Portanto, não se trata de pensar que esta demarcação de identidades/diferenças seja boa ou ruim, mas de que se dá por relações políticas, relações de poder, ou seja, pelas políticas de identidade, em práticas cotidianas que constituem sujeitos ao mesmo tempo em que redefinem tais marcadores •

\section{Notas}

1 A reportagem em questão foi publicada com o título: Tudo pelo popular". 0 caderno do jornal em que foi publicado ocupa-se de entrevistas, notícias, informações sobre comportamentos, cuidados com o corpo, vestuário, tendências das estações e da moda, pessoas consideradas celebridades, etc.

2 Aqui a noção de realidade e conhecimento guardam entre si estreita relação. "O conhecimento, como é visto na Modernidade, sempre é representação do mundo. Tem algo que é o mundo, e o conhecimento é a imagem desse mundo. 0 conhecimento é tanto mais viável, mais verdadeiro ou mais aceito quanto melhor representar essa realidade" (Iñiguez, 2002, p. 106). Esse modo de relação com a realidade modifica-se na Pósmodernidade, que põe em xeque a própria noção de realidade. Esta passa a ser concebida como uma construção do conhecimento. Como diz Veiga-Neto (1996) "...é o olhar que botamos sobre as coisas que, de certa maneira, as constitui (...) Em suma, o que importa não é saber se existe ou não uma "realidade real", mas, sim, saber como se pensa essa realidade" (p.27-28). Este é o cenário que dá condições de pensarmos em um diálogo entre 0 campo dos Estudos Culturais e a produção de sentidos na produção de conhecimentos em Psicologia Social.

3 Alguns desses autores são: Stuart Hall, Tomaz Tadeu da Silva, Alfredo Veiga-Neto, Marisa Costa, Rosa Maria Bueno Fischer, Dagmar Meyer e Sandra Corazza entre outros.

4 Bhabha (2001) usa o termo negociação para propor uma articulação entre elementos diferentes, mas sem entendêlos como antagônicos.

\section{Referências}

BAUMAN, Z. Modernidade Liquida. Rio de Janeiro: Jorge Zahar, 2001.

BHABHA, Homi K., O local da cultura. Belo Horizonte: Ed. UFMG, 1998.

DUSCHATZKY, S.; SKLIAR, C. O nome dos outros. Narrando a alteridade na cultura e na educação. In: LARROSA, J.; SKLIAR, C. (orgs). Habitantes de Babel: politicas e poéticas da diferença. Belo Horizonte: Autêntica, 2001.

FISCHER, R. Televisãa \& Educação: fruir e pensar a TV. Belo Horizonte: Autêntica, 2001. 
GUARESCHI, N. Políticas de Identidade: novos enfoques e novos desafios para a Psicologia Social. Psicologia e Sociedade, São Paulo, v. 12, p. 110-124, 2000.

HALL, S. A centralidade da cultura: notas sobre as revoluções do nosso tempo. Educação \& Realidade. Porto Alegre: ufrgs/faced, v.22, n.2, jul/dez, 1997, p. 15-46.

HÜNING, S. M. Ordinário Marche! A constituição e o governo de crianças/adolescentes pelo risco-diferença. Porto Alegre: PPG - Psicologia/PUCRS, 2003. Dissertação de Mestrado.

IÑIGUEZ, L.; HAMMOUTI, N.; MARTINS, J. B. (org). Temas em Análise Institucional e em Construcionismo Social. São Carlos: Rima, 2002.

SANTOS, L. Um preto mais clarinho... ou dos discursos que se dobram nos corpos produzindo o que somos. Educação $\&$ Realidade. Porto Alegre: UFRGS/FACED, v.22, n.2, jul/ dez, 1997, p. 81-115.

VEIGA-NETO, A. Olhares... In: COSTA, Marisa (org). Caminhos investigativos. Porto Alegre: Editora Mediação, 1996. 